\title{
PERCEPÇÃO AMBIENTAL DE ALUNOS DE ESCOLAS MUNICIPAIS INSERIDAS NO BIOMA MATA ATLÂNTICA
}

\author{
Ligia de Almeida Gilioli Fraga ${ }^{1}$ \\ Daniela Rocha Teixeira Riondet-Costa ${ }^{2}$ \\ Luciana Botezelli ${ }^{3}$
}

Resumo: $O$ estudo identificou a percepção ambiental de 148 alunos do ensino fundamental em Itajubá (MG) e a relação com o ambiente no qual vivem. Para tanto, adaptou-se o Método de Análise de Conteúdo de Bardin e as etapas do processo perceptivo de Del Rio. Foram definidas seis categorias perceptivas: Naturalista, Antropocêntrica, Globalizante, Romântica, Idílica e Não Identificada. Os alunos demonstram uma visão simplista sobre meio ambiente, na qual os elementos e representações são distantes do contexto local, compreendendo, na maioria, concepções Naturalistas. Portanto, é necessário melhorar a abordagem da Educação Ambiental nas escolas, buscando-se a concepção Globalizante na formação de sujeitos participativos e sensibilizados.

Palavras-chave: Educação Ambiental; Sensibilização Ambiental; Naturalista; Meio Ambiente.

Abstract: The study identified the environmental perception of 148 elementary school students in Itajubá (MG) and the relationship with the environment in which they live. To this end, the Bardin Content Analysis Method and the stages of Del Rio's perception process were adapted. Six perceptual categories were defined: Naturalist, Anthropocentric, Globalizing, Romantic, Idyllic and Unidentified. Students demonstrate a simplistic view of the environment, in which its elements and representations are distant from the local context, comprising mostly Naturalist conceptions. Therefore, it is necessary to improve the approach of environmental education in schools, seeking the Globalizing conception in the formation of participatory and sensitized subjects.

Keywords: Environmental Education; Environmental Awareness; Naturalist; Environment.

\footnotetext{
1Universidade Federal de Alfenas. E-mail: gilioli.bio@gmail.com, Link para o Lattes: http://lattes.cnpq.br/9637593119662166

2Universidade Federal de Itajubá. E-mail: daniela.unifei@gmail.com. Link para o Lattes: http://lattes.cnpq.br/6248878709762228

3Universidade Federal de Alfenas. E-mail: luciana.botezelli@gmail.com. Link para o Lattes: http://lattes.cnpq.br/9663804820756262
} 


\section{Introdução}

O homem exerce papel de destaque no cenário de degradação ambiental encontrado atualmente. Compreender esta relação torna-se fundamental e faz com que o meio ambiente seja um tema essencial nos âmbitos culturais, econômicos, políticos e sociais. A conservação do ambiente tem sido interpretada como modo de conciliar a preservação dos recursos naturais com seu uso sustentável e equilibrar esta relação dissociativa entre o homem e a natureza (MILLER, 2008).

Sendo assim, entender como são determinadas as experiências com o ambiente e o processo de sensibilização passaram a ser parte necessária nesse processo (GRENNO; PROFICE, 2019). A percepção ambiental é diferente para cada indivíduo, pois depende da cultura e da relação que foi estabelecida com a realidade local, sendo composta pelo conhecimento, valores e concepções pré-definidas sobre 0 ambiente em questão (SANTAELLA, 2012). Portanto, o modo como o mundo é interpretado, depende das correlações geradas em cada um, sendo que a interpretação difere de acordo com as vivências que ocorrem ao longo da vida.

Neste contexto, entende-se que as escolas são fundamentais para o processo perceptivo, como local no qual a aprendizagem começa a compor significado na formação de cada pessoa (SOUSA, 2017). Diante disto, este trabalho buscou identificar a percepção ambiental de 148 (cento e quarenta e oito) alunos da rede pública do município de Itajubá - Minas Gerais - inserido no bioma Mata Atlântica - a partir da concepção de meio ambiente que estes alunos possuem e, assim, determinar qual é a relação estabelecida com o ambiente no qual vivem.

\section{Fundamentação}

\section{Educação Ambiental - EA}

As intervenções ambientais causadas pelo homem compõem um quadro preocupante e foi a partir do ano de 1972, em Estocolmo, com a Conferência das Nações Unidas sobre Meio Ambiente Humano, que tais questões ganharam enfoque internacional (KRZYSCZAK, 2016).

Contudo, somente após ocorrer a I Conferência Intergovernamental sobre Educação Ambiental (EA) em Tbilisi, no ano de 1977, que esta foi compreendida como fundamental para se alcançar a sustentabilidade global (SORRENTINO et al., 2005; RODRIGUES et al., 2019). Para Macedo, Freitas e Venturin (2011) esta conferência foi responsável por interpretar o ambiente como composto por questões sociais e culturais, e não apenas pelo meio físico e biótico. Todos os encontros que se sucederam a este, fortaleceram as discussões e foram responsáveis pelo aperfeiçoamento das propostas norteadoras do tema. Assim, a EA: 
é conceituada como um processo que visa desenvolver uma população que seja consciente e preocupada com o meio ambiente e com os problemas que the são associados, e que tenha conhecimentos, habilidades, atitudes, motivações e compromissos para trabalhar individual e coletivamente na busca de soluções para os problemas existentes e para a prevenção dos novos (MACEDO; FREITAS; VENTURIN, 2011, p. 53).

De acordo com Azevedo et al. (2017), com o crescimento das discussões sobre a crise ambiental mundial e a preocupação com a preservação do ambiente, foi sancionada a lei 9.795/1999 que estabeleceu a Política Nacional de Educação Ambiental (PNEA) (BRASIL, 1999), definindo EA como:

Processos por meio dos quais o indivíduo e a coletividade constroem valores sociais, conhecimentos, habilidades, atitudes e competências voltadas para a conservação do meio ambiente, bem de uso comum do povo, essencial à sadia qualidade de vida e sua sustentabilidade (BRASIL, 1999).

Ruscheinsky (2004) e Sorrentino et al. (2005) apontam que há uma compreensão historicamente construída da problemática ambiental, sendo este um dos desafios a serem considerados pela EA para garantir novos paradigmas sociais e culturais, visto que, com uma análise das relações existentes entre o homem e a natureza pode-se perceber como os parâmetros sociais, culturais, econômicos e até mesmo históricos influenciam negativamente nesta questão.

Portanto, a compreensão da relação que o ser humano possui com o ambiente determinou-se através da EA como novos meios para harmonizar essas relações. Cabe destacar, que as pesquisas que buscam contribuir com as questões ambientais, adotam o conceito da EA crítica, onde a busca por práticas educativas eficientes e a maior participação social nestas questões, visam favorecer a democracia em relação ao meio ambiente (CORREA et al., 2016; AZEVEDO; RIONDET-COSTA; SANTOS, 2016).

A EA considerada crítica é aquela que abrange as dinâmicas sociais vivenciadas pelas problemáticas ambientais, buscando a transformação da realidade (SORRENTINO et al., 2005). A partir desta complexa relação, surgem os meios para buscar modificações na realidade socioambiental, através da crítica, na qual "o conflito, as relações de poder são fundamentais na construção de sentidos, na organização espacial em suas múltiplas determinações" (GUIMARÃES, 2004, p. 28). 
A Educação Ambiental crítica, é aquela que em síntese busca pelo menos três situações pedagógicas: a) efetuar uma consistente análise da conjuntura complexa da realidade a fim de ter os fundamentos necessários para questionar os condicionantes sociais historicamente produzidos que implicam a reprodução social e geram a desigualdade e os conflitos ambientais; b) trabalhar a autonomia e a liberdade dos agentes sociais ante as relações de expropriação, opressão e dominação próprias da modernidade capitalista; c)implantar a transformação mais radical possível do padrão societário dominante, no qual se definem a situação de degradação intensiva da natureza e em seu interior, da condição humana (LOUREIRO; LAYRARGUES, 2013, p. 64).

Sendo assim, entende-se que a concepção de busca por um novo modelo social, no qual a EA crítica acontece e se fortalece, permite que os meios de reprodução social e a relação entre homem e ambiente façam com que se verifique, inevitavelmente, a responsabilidade que o contexto possui pela situação ambiental atual (LOUREIRO; LAYRARGUES, 2013; CORREA et al., 2016; RODRIGUES et al., 2019).

Portanto, a EA pode ocorrer em espaços de educação formal ou não formal, sendo compreendida como um direito de todos, e que, quando é significada por projetos e programas, o público-alvo pode variar entre crianças, jovens e adultos (BARBOSA et al., 2018; MACEDO; FREITAS; VENTURIN, 2011). Todavia, faz parte da realidade de todos e a aprendizagem é contínua.

\section{Educação Ambiental e o sistema de ensino}

A EA possui como sentido fundamental estabelecer processos práticos e reflexivos que consolidam os valores sociais, os quais devem ser compreendidos como favoráveis à sustentabilidade global, à justiça social e à preservação da vida, garantindo os princípios do art. 225 da Constituição Federal (LOUREIRO, 2004; BRASIL, 1988; RODRIGUES, 2019). Na escola, é compreendida como tema interdisciplinar podendo ser trabalhada por todas as disciplinas de forma transversal, conforme determina a PNEA (BEHREND; COUSIN; GALIAZZI, 2018; BRASIL, 1999).

A EA como tema do ensino, surge com fins de valorização da moral humana no âmbito social, sendo atualmente expandida para compreender também a natureza que passou a ser parte dos efeitos das ações humanas. De acordo com esta compreensão, a problemática ambiental no contexto social possui caráter ético e ecológico ao buscar promover uma transformação cultural, quanto à relação humana com a natureza (LAYRARGUES, 2006; FESTOZO et al., 2018; BARBOSA et al., 2018).

No Brasil, a formulação da EA se iniciou no contexto educacional vigente e, portanto, implicava em se adequar às características políticas, sociais e 
culturais do período, que era considerado conservacionista e técnico (LIMA, 2009; RIONDET-COSTA, 2012). Concomitantemente, Layrargues (2006) destaca que mesmo com o amplo aspecto de mudança social representado pela EA, esta ainda se encontra vinculada a um sistema de ensino que se apresenta ineficiente:

[...] uma conjunção de fatores (como a concepção naturalista de meio ambiente, o predomínio de profissionais oriundos da biologia como educadores ambientais, o predomínio de órgãos governamentais ambientais como proponentes de políticas e programas de Educação Ambiental, a omissão científica na incorporação da Educação Ambiental como um objeto de estudo da sociologia ambiental e da sociologia da educação) acarretou na ecologização da Educação Ambiental, moldandoa conforme o modelo de uma educação conservacionista [...] (LAYRARGUES, 2006, p. 6).

Para modificar estas concepções, a EA deve ser compreendida como um fenômeno transformador de práticas pedagógicas (BEHREND; COUSIN; GALIAZZI, 2018). Portanto, é necessário que o conhecimento seja assimilado e passe a ser praticado pelos indivíduos de modo participativo em discussões que culminem na tomada de decisões a respeito da problemática ambiental (REIGOTA, 2007).

\section{Percepção Ambiental}

De acordo com Del Rio (1996), a percepção de um indivíduo determina a compreensão do ambiente como um processo mental que ocorre através de meios perceptivos (sensações e motivações) e cognitivos (cognição, conduta e avaliação) que representam os conhecimentos prévios, valores e julgamentos de cada indivíduo. Neste sentido, demonstra que as experiências vivenciadas pelo ser humano não ocorrem de forma passiva e a interpretação destas experiências como "motivações, humores, necessidades, conhecimentos prévios, valores, julgamentos e expectativas" (p.3), se constroem conforme novas experiências ocorrem e moldam esta percepção ambiental.

Para Yi-fu Tuan (1980), busca-se através da percepção identificar as atitudes e valores que regem a sociedade a partir de cada indivíduo, em particular. Tais experiências não devem ser desvalorizadas, visto que o homem interfere no ambiente, o que faz com que seu comportamento deva ser devidamente compreendido. Estes fatores são traços da constante autoconstrução do ser humano e o modo de se relacionar com o mundo.

A questão gerada pela percepção, na passagem das informações sensoriais para o cérebro, é a tomada da consciência, que vai além do ato de perceber. Sendo assim, a mente é responsável por constituir o mundo a partir do que the é oferecido pelos sentidos (SANTAELLA, 2012). 
Os estudos sobre a percepção do ambiente pelo homem são fundamentais para compreender as inter-relações entre homem e ambiente, pois buscam "investigar como o homem enxerga, interpreta, convive e se adapta à realidade do meio em que vive, principalmente em se tratando de ambientes instáveis ou vulneráveis social e naturalmente" (SANTOS; SOUZA, 2015, p. 6).

\section{Metodologia}

A presente pesquisa é classificada como qualitativa; quanto ao objetivo se classifica em exploratória; conforme o local, é classificada como uma pesquisa de campo (SOUZA et al., 2013).

Quanto ao público-alvo, participaram 148 (cento e quarenta e oito) alunos de seis turmas do $5^{\circ}$ ano do Ensino Fundamental I, de três escolas municipais de Itajubá/MG (bioma Mata Atlântica). As escolas foram chamadas de $A, B$ e $C$ como modo de garantir o sigilo dos questionados, enquanto as turmas foram divididas em Turma 1 e Turma 2 para cada escola. A escolha deste nível de ensino se deu pelo fato de que crianças deste ano escolar, segundo Piaget (2010), possuem maior facilidade com a escrita, habilidades para desenvolver críticas e propor novos valores morais.

Destes, solicitou-se que elaborassem uma redação onde foi apresentada uma situação problema visando identificar o nível de percepção que possuíam sobre o ambiente que os rodeia. A situação foi apresentada por meio de uma tirinha da Turma da Mônica onde o personagem Chico Bento dialogava com a personagem Rosinha sobre o primo, que morava na cidade e sentia falta da natureza.

A organização dos dados ocorreu via a adaptação do Método de Análise de Conteúdo, proposto por Bardin (1977). Foi realizada a leitura do material destacando-se as palavras-chaves e frases (Unidades de Registro) que geraram as percepções sobre meio ambiente. Posteriormente, estas unidades foram separadas em Categorias de acordo com as semelhanças e diferenças.

Utilizando os conceitos de meio ambiente de Reigota (2007), Ramos (2006), Rodrigues e Malafaia (2009) definiram-se as 5 (cinco) categorias a partir das Unidades de Registro identificadas: Concepções Naturalista, Antropocêntrica, Globalizante, Idílica e Romântica. A definição destas categorias priorizou os conceitos que mais aparecem na literatura e que surgem em pesquisas de Educação Ambiental e Percepção Ambiental, conforme demonstrados no Quadro 1. 
Quadro 1: Categorias definidas pela adaptação da análise de conteúdo.

\begin{tabular}{|c|c|c|}
\hline & \multicolumn{2}{|r|}{ PERCEPÇÃO AMBIENTAL } \\
\hline \multirow{6}{*}{ CATEGORIAS } & $\begin{array}{l}\text { Concepção } \\
\text { Naturalista }\end{array}$ & $\begin{array}{l}\text { Nesta percepção, se encaixam as definições que associam a } \\
\text { ideia de Meio Ambiente à de ecossistema, priorizando seus } \\
\text { aspectos naturais, como fauna, flora e aspectos físico- } \\
\text { químicos (REIGOTA, 2007). }\end{array}$ \\
\hline & $\begin{array}{l}\text { Concepção } \\
\text { Antropocêntrica }\end{array}$ & $\begin{array}{l}\text { Considera o meio ambiente/natureza como fonte de recursos } \\
\text { a serem utilizados e gerenciados pelo homem (REIGOTA, } \\
\text { 2007). }\end{array}$ \\
\hline & $\begin{array}{l}\text { Concepção } \\
\text { Globalizante }\end{array}$ & $\begin{array}{l}\text { Esta percepção coloca o homem em relação com os demais } \\
\text { elementos, sem domínio, engloba aspectos sociais, naturais, } \\
\text { políticos, econômicos, filosóficos e culturais (REIGOTA, } \\
\text { 2007). }\end{array}$ \\
\hline & $\begin{array}{l}\text { Concepção } \\
\text { Idílica }\end{array}$ & $\begin{array}{l}\text { Trata-se de uma percepção cuja visão de meio } \\
\text { ambiente/natureza é fantasiosa e seus problemas } \\
\text { compreendidos como algo utópico, distante de ser alcançado } \\
\text { (MELLO; TRAJBER, 2007). }\end{array}$ \\
\hline & $\begin{array}{l}\text { Concepção } \\
\text { Romântica }\end{array}$ & $\begin{array}{l}\text { Compreende a visão de natureza como mãe natureza e esta } \\
\text { é percebida como harmônica e equilibrada, sendo sempre } \\
\text { interpretada como um local de beleza estética. O homem não } \\
\text { está inserido neste processo. Nesta percepção há a } \\
\text { dualidade entre o homem e a natureza (RODRIGUES; } \\
\text { MALAFAIA, 2009). }\end{array}$ \\
\hline & $\begin{array}{l}\text { Concepção não } \\
\text { identificada }\end{array}$ & $\begin{array}{l}\text { Percepções que não puderam ser identificadas nos textos } \\
\text { dos alunos. }\end{array}$ \\
\hline
\end{tabular}

Fonte: As autoras (2020).

\section{Resultados e Discussão}

A categoria Concepção Naturalista (Figura 1), foi a mais expressiva nas três escolas estudadas, sendo identificada em aproximadamente $60 \%$ dos 148 textos analisados. Nestes textos o foco foi o aspecto natural, principalmente a flora, onde foram citadas florestas, árvores e mato como meio ambiente. Corroborando este resultado têm-se os estudos de Buss e Silva (2020), Krzysczak (2016), Reigota (2007) e Ramos (2006), nos quais identificaram a concepção naturalista também como a de maior destaque.

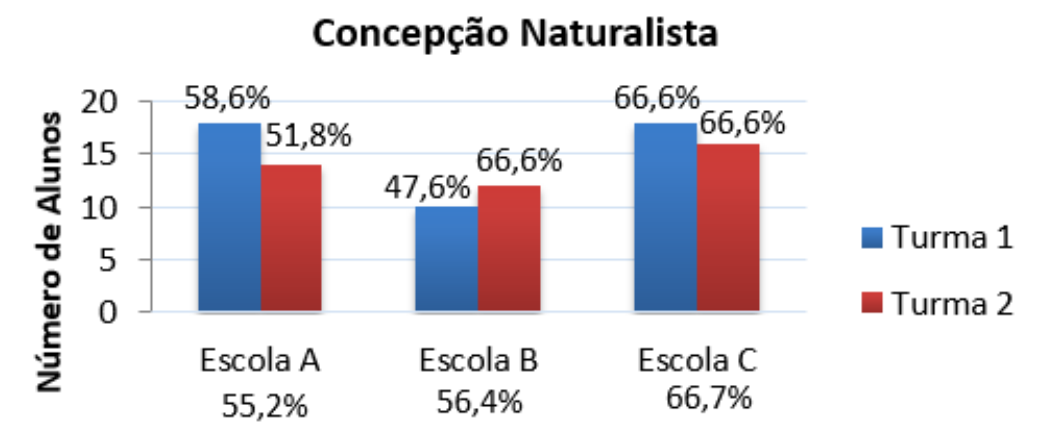

Figura 1: Porcentagem dos textos dos alunos identificados como concepção naturalista, distintos por escolas e turmas.

Fonte: As autoras (2020). 
Este modo de retratar o ambiente exclui os demais elementos que o compõem, como os seres humanos por exemplo. Tais trechos acabam reforçando a ideia de que o meio ambiente é um local intocado e com muitas árvores (elemento de maior destaque), conforme demonstrado a seguir:

O primo do Chico Bento pode passar mais tempo na casa do Chico, pois lá tem bastante árvore. Ele também podi ir em lugares com bastante árvores, pássaros, rios... (Aluno 9, Turma 2 - Escola B).

Outro aspecto importante da Concepção Naturalista foi a noção de meio ambiente distanciada da urbanização. O texto a seguir exemplifica esta visão:

O primo de Chico Bento precisa criar um meio ambiente dentro de sua cidade, ele precisa achar um lugar que tem gramado $e$ que passasse carro ali, mas não vai ser igual porque, a água do rio é muito e não vai dar pra pescar, o rio teria que ser bem limpo, é na roça é bem diferente o único jeito de eu ficar em um ambiente mais limpo a cidade é muito suja comparado a roça (Aluno 8, Turma 1 - Escola C).

Esta situação foi observada nos textos que abordaram o meio ambiente como ambiente rural por ser um local, normalmente, com muitas árvores, pouca poluição visível, animais e ar puro. De acordo com Reigota (2007), a Percepção Naturalista se encaixa nos conceitos de meio ambiente que são confundidos com os elementos do ecossistema, que prioriza aspectos naturais, como a fauna, a flora e os elementos físico-químicos.

Também foram definidos como naturalistas os textos que apresentaram enfoque em ações, realizadas como regras, como por exemplo: não queimar as matas, jogar lixo no lixo, não matar os animais, como se tais ações pudessem ser consideradas suficientes para a resolução dos problemas ambientais:

Devemos cuidar da natureza, impedindo pessoas de matá-la, não colocar fogo, não cortar as árvores, não jogar lixo no chão e sim nas lixeiras corretas. Se corta-las, colocar uma semente para que possa nascer outra no lugar. Jogando o lixo no chão podemos matar algum animal e sempre mantendo a água de algum rio limpo (Aluno 7, Turma 2 - Escola A).

Segundo Ramos (2006), há uma tendência naturalista de correlacionar a problemática ambiental à soluções pouco ou nada eficientes, sendo que na escola a propagação desta visão não leva em consideração as transformações que podem acontecer nas interações entre os elementos que compõem a relação entre 0 homem e 0 meio ambiente e no processo de ensinoaprendizagem escolar e, neste contexto, "os problemas ambientais tendem a ser naturalizados e entendidos como se fossem de ordem 'natural"' (p. 52), 
distanciando-se de uma compreensão do ambiente que inclua todos os elementos que o compõem.

Segundo as definições de percepção ambiental propostas por Del Rio (1996), esta categoria pode ser analisada pela etapa de sensações, pois a percepção naturalista é influenciada pelos sentidos (tato, visão, audição, paladar e olfato).

A segunda categoria apresentada trata da Concepção Antropocêntrica e agrupa os textos que colocam o meio ambiente à serviço das pessoas (Figura 2). Esta visão, com viés utilitarista surgiu em aproximadamente $11,5 \%$ dos 148 textos analisados. Os alunos que expressaram estas opiniões especificaram que o ser humano interpreta os recursos naturais como bens e serviços.

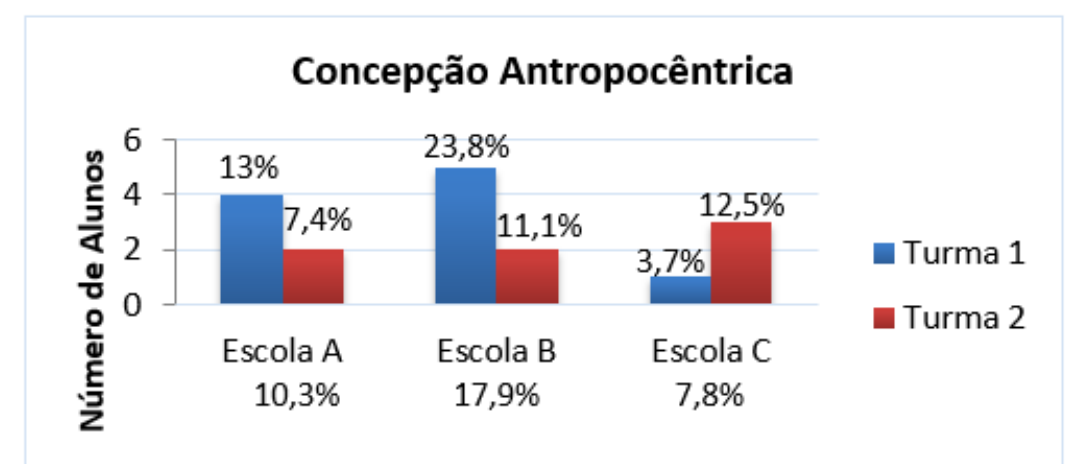

Figura 2: Porcentagem dos textos dos alunos identificados como concepção antropocêntrica, distintos por escolas e turmas.

Fonte: As autoras (2020).

Esta categoria foi menos expressiva em relação à anterior, com $17 \%$ de frequência e pode-se considerar, de acordo com as concepções identificadas nos textos, que ainda há prevalência da visão naturalista, mas com o ambiente sendo retratado como um recurso necessário e utilizado pelas pessoas. Ainda, há uma ideia maior sobre a importância de se preservar o ambiente, mas voltada ao uso dos recursos naturais, devido à uma característica utilitarista, conforme demonstrado no texto a seguir:

Não jogar lixo nos rios, não poluir a água, temos que preservar a natureza e não destrui-la pois ela vai servir para as gerações futuras. Não desperdiçar a energia e água, pois a água e o nosso bem mais precioso sem ela nós não existiríamos (Aluno 11, Turma 1 - Escola B).

Os autores Fernandes, Cunha e Júnior (2002) obtiveram, em uma pesquisa com profissionais da educação, que aproximadamente $35 \%$ das concepções identificadas sobre meio ambiente estavam relacionadas à visão antropocêntrica, concluindo que o desinteresse crescente pelas questões ambientais, tanto em âmbito individual quanto coletivo podem ser originadas desta visão que se encontra enraizada na civilização, na qual os humanos se 
colocam como núcleo central em detrimento ao meio ambiente. A nível de ensino, estes profissionais que também passaram pelo processo educativo, disseminariam esta visão.

Neste sentido, Santaella (2012) corrobora este achado ao descrever a percepção como um processo que é composto e se configura por meios afirmados e não a uma simples resposta aos estímulos do ambiente, configurando o ambiente como aquilo que é percebido e que irá estimular a percepção. Portanto, aquilo que é vivenciado fará parte das experiências que são propagadas, para Tuan (1980, p. 31), "a criança é o pai do homem e as categorias perceptivas do adulto são de vez em quando impregnadas de emoções que procedem das primeiras experiências". Deste modo, as conexões estabelecidas no dia a dia podem contribuir ao dar significado ao aprendizado.

Segundo as etapas de percepção descritas por Del Rio (1996), esta categoria também se enquadra como na primeira etapa, de sensações, pois esta percepção também é influenciada pelos sentidos (tato, visão, audição, paladar e olfato). Isto também se explica pelas descrições realizadas pelos alunos de forma simplistas e com pouca, ou nenhuma, criticidade.

Outra categoria identificada foi a Concepção Romântica (Figura 3). Esta categoria está entre as que surgiram com menor frequência (11\%), sendo que na Turma 2 da Escola $C$ a frequência foi zero. Nela, o meio ambiente é a imagem idealizada de algo esteticamente bonito, visualmente prazeroso, onde coisas boas tendem a acontecer.

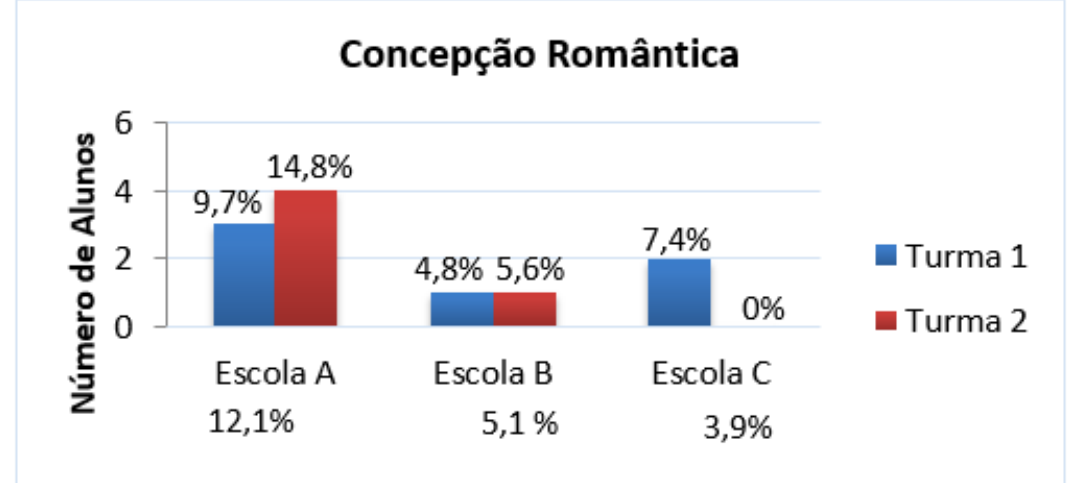

Figura 3: Porcentagem dos textos dos alunos identificados como concepção romântica, distintos por escolas e turmas.

Fonte: As autoras (2020).

Nesta categoria, o ser humano e suas ações aparecem como elementos dissociados deste contexto e isto pode ocorrer devido à compreensão de que o homem prejudica este espaço que é compreendido como harmônico e equilibrado.

O primo pode faze o diferemsa na cidade do jeito dele. tipo começar a plantar e colher. Para mim o meio ambiente e um lugar de amor a naturesa é um lugar de satisfatorisação e felisidade (Aluno 26, Turma 1 - Escola C). 
Semelhante à Concepção Romântica, a Concepção Idílica também foi encontrada em poucos textos. Os três alunos identificados nesta concepção (Figura 4) apresentam uma noção fantasiosa sobre o ambiente que os cerca e descrevem propostas que podem ser consideradas utópicas, uma vez que as soluções para os problemas ambientais carecem de estudos, tempo e dedicação para que sejam resolvidos e isto inclui a modificação dos comportamentos sociais almejada pela EA.

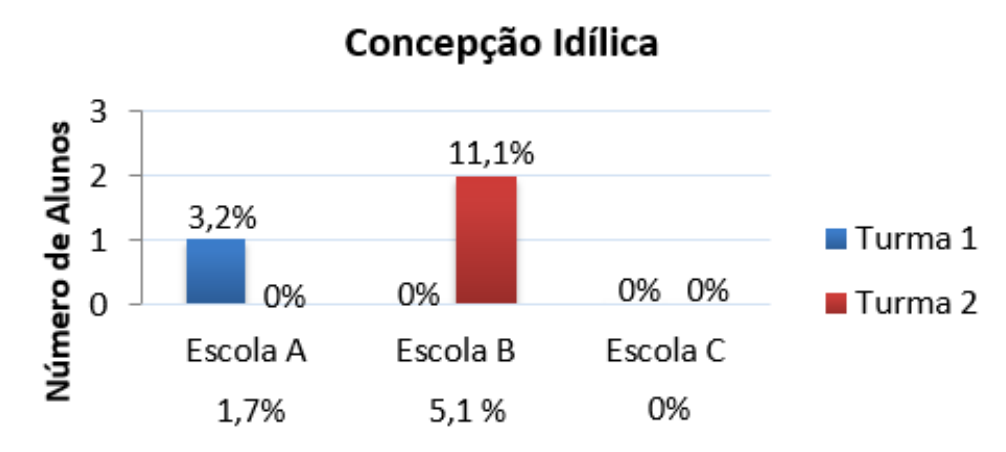

Figura 4: Porcentagem dos textos dos alunos identificados como concepção idílica, distintos por escolas e turmas.

Fonte: As autoras (2020).

Foi possível identificar nestes textos que a solução para a questão problema da atividade - sentir falta do meio ambiente na cidade - poderia ser resolvida ao se conviver mais com a roça. Um exemplo destes textos é apresentado a seguir:

- Oi primo o que eu estou querendo dizer que. No interior não tem carro porque qui tivese não prejudicaria o meio ambiente e também não seria fabricado por idustria. e sim dos animais. (Aluno 1, Turma 1 - Escola A).

Esta influência que as Concepções Romântica e Idílica inferem, pode estar relacionada às sensações que são provocadas pelo ambiente nestes alunos e, neste sentido, trata-se da topofilia do ambiente enquanto descrito como um espaço idealizado sem interferência humana, sendo este o fator que confere a qualidade deste meio. Assim, estas categorias também pertenceriam a primeira etapa do processo perceptivo descrito por Del Rio (1996), que seria o de sensações.

A Concepção Globalizante expõe uma interpretação que compreende o ambiente em um sentido mais amplo, coloca o ser humano em relação de igualdade com a natureza e traz aspectos críticos (Figura 5). Dentre os 148 textos analisados, aproximadamente $14,9 \%$ foram identificados nesta categoria que pode ser considerada como a mais importante, pois engloba aspectos naturais, políticos, sociais, econômicos, filosóficos e culturais. Neste sentido, a 
categoria de Concepção Globalizante se aproxima da definição de meio ambiente:

O lugar determinado ou percebido, onde os elementos naturais e sociais estão em relações dinâmicas e em interação. Essas relações implicam processos de criação cultural e tecnológica e processos históricos e sociais de transformação do meio natural e construído (REIGOTA, 2007, p.14).

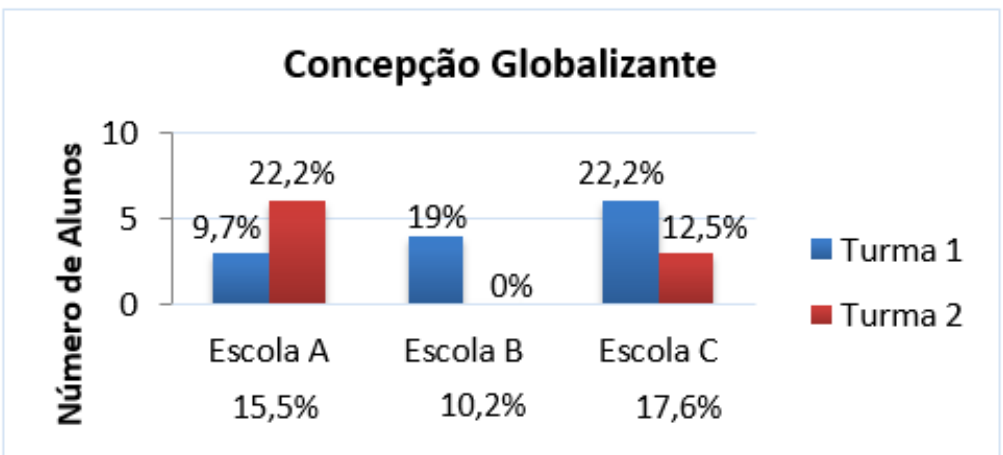

Figura 5: Porcentagem dos textos dos alunos identificados como concepção globalizante, distintos por escolas e turmas.

Fonte: As autoras (2020).

Destaca-se ainda que houve uma variação perceptível entre as turmas e entre as escolas na quantidade de textos identificados nesta categoria. $O$ texto a seguir elucida esta categoria:

Para melhorar o meio ambiente é preciso ter respeito por ele. Algumas formas de mostrar respeito é não jogando lixo em rios, lagos, ruas e praças, não desmatar sem ser necessário, não começar incêndios sem necessidade e que prejudiquem muito a natureza, não caçar animais, principalmente os que sofrem de extinção, troque carros ou motos por bicicletas ou até andar a pé. Com essas dicas você terá um mundo bem melhor. (Aluno 2, Turma 2 - Escola B).

A Concepção Globalizante permite identificar que os alunos demonstram reconhecer o ambiente, sendo este um dos objetivos da EA quando trabalhada nos espaços formais de ensino, visto que a Política Nacional de Meio Ambiente a define como o meio para formar os indivíduos, por processos que "constroem valores sociais, conhecimentos, habilidades, atitudes e competências voltadas para a conservação do meio ambiente" (BRASIL, 1999), identificados pela percepção ambiental, evidenciando as relações entre sociedade e ambiente $e$ 
nesta perspectiva, o conceito de meio ambiente não se refere apenas aos elementos naturais, sejam eles orgânicos ou inorgânicos, mas como um bem comum, espaço de ação política, porque também produto das relações que os homens estabelecem entre si. Portanto, o meio ambiente é um bem coletivo (RAMOS, 2006, p. 62).

No entanto, esta compreensão se apresenta bastante simplista na maioria nos textos analisados e alguns textos ainda apresentam vestígios de ideias que foram classificadas em outras categorias. Isto pode evidenciar que os alunos possuem dificuldade para expressar opiniões críticas em relação ao tema.

Deste modo esta categoria, segundo Del Rio (1996), poderia ser classificada na etapa de motivação, que representa o início das representações mentais da percepção ambiental, na qual há influências tanto individuais quanto coletivas a partir de necessidades e interesses.

A última categoria, Concepção Não Identificada, contém textos que não foram condizentes com as propostas do enunciado da questão (Figura 6).

Foram sete textos que corresponderam a esta categoria e representam $4,7 \%$ do total da amostra, sendo que na Turma 1 da Escola $C$ o número foi zero. As respostas inclusas nesta categoria foram evasivas, sem clareza, ou confusas e outras ainda apresentaram concepções misturadas que dificultaram sua classificação.

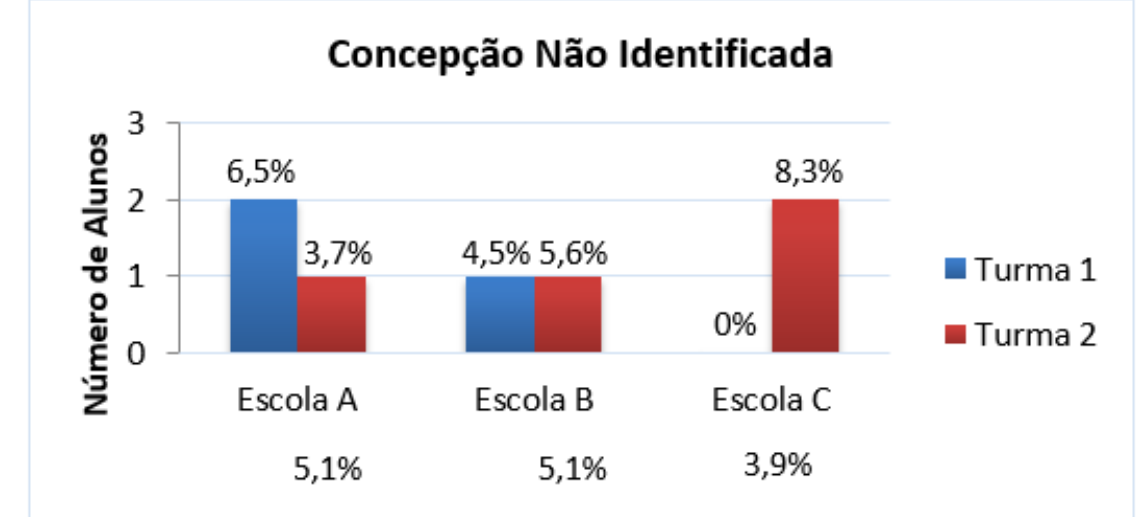

Figura 6: Porcentagem dos textos dos alunos identificados como concepção não identificada, distintos por escolas e turmas.

Fonte: As autoras (2020).

Alguns textos desta categoria são apresentados a seguir:

Era uma veis xicobeto e rozinha estava fazeno piquiniqui ai eli neadar andaro até que fin e haruu ai rozinha abiu olensou xico bento pegou toda as coiza. Ai xco bento falo? Que suco. É la repm. De (entende-se como ela respondeu) qero sim tabou você que bolo tambei éla respmddu (entende-se como 
respondeu) qero sim muto obigado tabou ai os doi comesamu acomer fim (Aluno 8, turma 1 - Escola A).

Você poderia ir ao parque fazer um passeio, no parque ou um piquenique, ou brincar no parque jogar futebol, na grama ou pescar (Aluno 19, turma 1 - Escola A).

A flor adormecida. Um dia no meio de um jardim havia uma flor que e todas as flores falavam que ela adormecida até a 100 anos. A flor começou adormecer por 100 anos e ela nunca acordava (Aluno 20, turma 1 - Escola B).

Os resultados gerais das categorias de concepção identificadas podem ser visualizados na Figura 7. Observa-se que, a formação de pessoas reflexivas, com senso crítico e capazes de promover atitudes e valores fundamentais mais sustentáveis ao convívio em sociedades estaria em etapas do processo perceptivo, segundo Del Rio (1996), como as etapas de cognição, conduta e avaliação e, dentre as categorias obtidas nesta pesquisa, tais etapas não foram identificadas nos textos dos alunos.

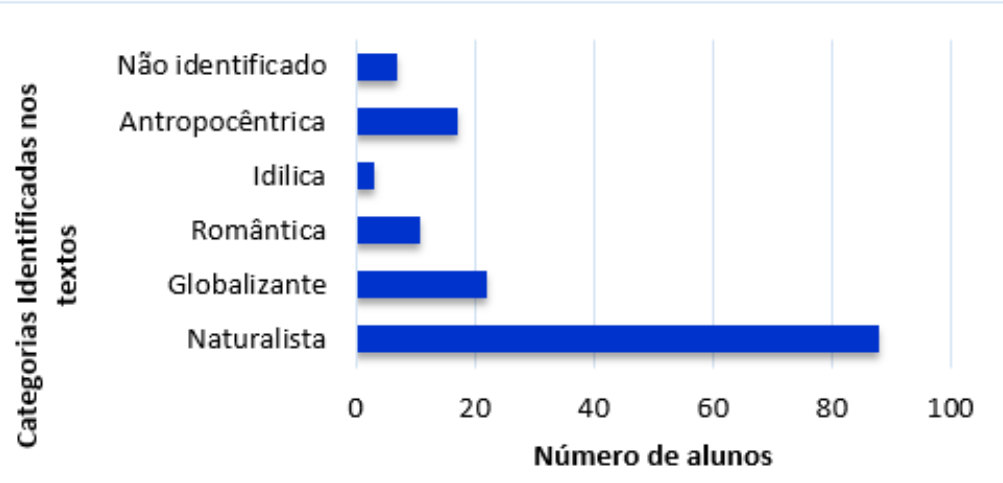

Figura 7: Porcentagem geral dos textos dos alunos distintos pelas concepções identificadas.

Fonte: As autoras (2020).

Sendo assim, de modo geral é possível identificar que, nas concepções de ambiente demonstradas, há pouco vínculo com a realidade na qual eles estão inseridos. Mesmo na categoria Concepção Globalizante, que trata do ambiente como um todo, os textos demonstraram que os alunos não possuem uma visão holística, sendo que as referências que possuem partem de âmbitos globais, com alguns alunos que citaram elementos e ações próximas do ambiente no qual estão inseridos. Oliveira e Nogueira (2019) identificaram em alunos do ensino fundamental e da Educação de Jovens e Adultos (EJA) uma visão semelhante à encontrada neste estudo.

Os achados corroboram para a necessidade de que o ensino da EA perpasse o contexto de sala de aula e seja efetivamente relacionado ao ambiente ao qual o aluno pertence, para que seja capaz de ser ativo, crítico e sensibilizado para a temática ambiental. 


\section{Considerações Finais}

Compreender a importância do meio ambiente para a sociedade é fundamental para que se alcancem práticas mais sustentáveis e condizentes com o equilíbrio ambiental. O estudo da percepção ambiental é de grande importância para agregar significados para o modo como a aprendizagem deste tema ocorre nas escolas.

De acordo com os resultados considerados, a percepção ambiental encontrada na categoria de Concepção Globalizante é considerada fundamental para o processo de EA de cada indivíduo. Para que todos os alunos possam desenvolver-se criticamente e envolver em suas ideias todos os elementos que compõem o ambiente em que estão inseridos, é necessário vincular o ensino de temáticas ambientais à realidade local para que haja a construção de significados mais expressivos para cada um. Ainda, para compreender o ambiente no qual se vive, o papel que deve ser exercido enquanto cidadão sensibilizado pode ser considerado um passo importante para influenciar em problemáticas de âmbito global.

Portanto, é necessário fortalecer a concepção globalizante expandindo os conceitos trabalhados pela EA nas escolas, problematizando as questões ambientais dentro e fora da sala de aula na busca por um ensino que permeie todos os aspectos que compõem o ambiente. Neste contexto, o uso de estratégias que remetam e favoreçam a percepção ambiental é um meio para evidenciar o modo como o ser humano compreende o ambiente que o cerca e, a partir disto, elaborar ações de EA mais reflexivas, pró-ativas e questionadoras da realidade, buscando evidenciar uma práxis que permita aos alunos serem críticos, ativos, se sintam inseridos e responsáveis pelo ambiente no qual vivem e para que haja significativa compreensão do papel fundamental que cada indivíduo representa na sociedade.

\section{Agradecimentos}

À coordenação de aperfeiçoamento de pessoal de nível superior (CAPES), pelo apoio financeiro à pesquisa através de bolsa de mestrado. Ao programa de Pós-Graduação em Meio Ambiente e Recursos Hídricos da Universidade Federal de Itajubá (UNIFEI) e ao Programa de Pós-Graduação em Ciências Ambientais da Universidade Federal de Alfenas (UNIFAL).

\section{Referências}

AZEVEDO, L.V.; RIONDET-COSTA, D.R.T.; SANTOS, J.R. Política Nacional de Educação Ambiental: Análise de sua aplicação em projetos de pesquisa e extensão de instituições públicas de ensino. Ciência e Natura, Santa Maria, v.39, n.3, p. 701-722, set./dez. 2016. 
AZEVEDO, L.V.; ALEXANDRINO, S.A.; SILVA, J.L.M.; RIONDET-COSTA, D.R.T. Educação Ambiental e Legislação: Reflexões sobre participação e efetividade. Revista Brasileira de Educação Ambiental, São Paulo, v. 12, n. 2, p. 284-295, 2017.

BARDIN, L. Análise de conteúdo. Edições 70, São Paulo. 1977. 220 p.

BARBOSA, A.M.F.; SOUZA, D.S..; FREITAS, J.A..; AZEVEDO, M.M. Educação Ambiental para a Participação Social. Revista Sergipana de Educação Ambiental, v. 5, n. 5, p. 28-36, 2018.

BEHREND, D.M.; COUSIN, C.S.; GALIAZZI, M.C. Base Nacional Comum Curricular: $O$ que se mostra de referência à Educação Ambiental? Ambiente e Educação - Revista de Educação Ambiental, v. 23, n. 2, p. 74-89, 2018.

BRASIL. Constituição da República Federativa do Brasil, de 05 de outubro de $1988 . \quad$ Disponível em: $<$ http://www.planalto.gov.br/ccivil 03/constituicao/constituicao.htm>. Acesso em 20/12/2018.

BRASIL. Lei no. 9.795 de 27 de abril de 1999. Institui a Política Nacional de Educação Ambiental. Diário Oficial [da] República Federativa do Brasil. Brasília, DF, Disponível em: <http://www.planalto.gov.br/ccivil 03/leis/19795.htm>. Acesso em: 26/01/2018.

BUSS, A.; SILVA, M.M. Percepção Ambiental de alunos que viveram o maior desastre-crime ambiental do Brasil: implicações para a Educação Ambiental. Revista eletrônica do Mestrado em Educação Ambiental, Rio Grande, v. 37, n. 1, p. 47-67. jan./abr. 2020.

CORREA, F.V..; PRAÇA, M.F..; LOUREIRO, C.F.B..; FRANCA, N. Contribuições da Educação Ambiental para a gestão integrada em mosaicos de áreas protegidas: O Caso do Mosaico Central Fluminense (RJ). Revista Brasileira de Educação Ambiental, São Paulo, v. 11, n. 2. 2016.

DEL RIO, V. Cidade da mente, cidade real: Percepção Ambiental e revitalização na área portuária do RJ. In: DEL RIO, V..; OLIVEIRA, L. (Org.) Percepção Ambiental: A experiência Brasileira. São Paulo: Studio Nobel; São Carlos, SP: Universidade Federal de São Carlos, 1996. 255p.

FERNANDES, E.C..; CUNHA, A.M.O..; JÚNIOR, O.M. Educação Ambiental e meio ambiente: concepções de profissionais da educação. Anais do II Encontro Nacional de Pesquisadores em Educação Ambiental. São Carlos, 2002.

FESTOZO, M.B.; QUEIXAS, R.C.; JUNIOR, A.F.N.; TOZONI-REIS, M.F.C. Relações Históricas entre a Educação Ambiental e a Participação Social. Revista Tempos e Espaços em Educação, São Cristóvão, Sergipe, Brasil, v. 11, n. 24, p. 253-266, jan./mar. 2018. 
GRENNO, F.E.; PROFICE, C.C. Experiências diretas entre crianças e natureza-educar para a sustentabilidade. Revista Eletrônica do Mestrado em Educação Ambiental, Rio Grande, v. 36, n. 1, p. 324-338. jan./abr. 2019.

GUIMARÃES, M. Educação Ambiental Crítica. In: Philippe Pomier Layrargues (coord.). Identidades da Educação Ambiental Brasileira. Diretoria de Educação Ambiental;-- Brasília: Ministério do Meio Ambiente, 2004. 156 p.

GUIMARÃES, M. Por uma Educação Ambiental Crítica na sociedade atual. Revista Margens Interdisciplinar, [S.I], v. 7, n.9, p. 11-22, mai. 2016.

KRZYSCZAK, F.R. As diferentes concepções de meio ambiente e suas visões. Revista de Educação do Instituto de Desenvolvimento Educacional do Alto Uruguai, v. 11, n. 23, Jan./Jun. 2016.

LAYRARGUES, P.P. Muito além da natureza: Educação Ambiental e reprodução social. In: LOUREIRO, C.F.B..; LAYRARGUES, P.P.; CASTRO, R.S. (Orgs.) Pensamento complexo, dialética e Educação Ambiental. São Paulo: Cortez. p. 72-103. 2006.

LIMA, G.F.C. Educação Ambiental crítica: do socioambientalismo às sociedades sustentáveis. Educação e Pesquisa, São Paulo, v.35, n.1, p. 145163, jan./abr. 2009.

LOUREIRO, C.F.B. Educar, participar e transformar em Educação Ambiental. RevBEA, Brasília, n. 0. p. 13-20. 2004.

LOUREIRO, C.F.B.; LAYRARGUES, P.P. Ecologia política, justiça e Educação Ambiental crítica: perspectivas de aliança contra-hegemônica. Trabalho, Educação e Saúde, Rio de Janeiro, v.11, n.1, p.53-71,jan./abr. 2013.

MACEDO, R.L.G..; FREITAS, M.R..; VENTURIN, N. Educação Ambiental: referenciais teóricos e práticos para a formação de educadores ambientais. Lavras: UFLA, 2011. p. 258.

MILLER, G.T. Ciência Ambiental. Tradução All Tasks. 11. ed. São Paulo: Cengage Learning, 2008. 501p.

OLIVEIRA, E.T.; NOGUEIRA, C. Um estudo das concepções de Educação Ambiental de alunos regulares e da Educação de Jovens e Adultos do Ensino fundamental. Revista eletrônica do Mestrado em Educação Ambiental, Rio Grande, v. 36, n. 1, p. 357-373. jan./abr. 2019.

PIAGET, J. A formação do símbolo na criança: imitação, jogo e sonho, imagem e representação. 4ª ed. Rio de Janeiro: LTC, 2010.

RAMOS, E.C. A abordagem naturalista na Educação Ambiental: uma análise dos projetos ambientais de educação em Curitiba. 2006. 241f. Tese (Doutorado em Ciências Humanas), Universidade Federal de Santa Catarina, Centro de Filosofia e Ciências Humanas, Florianópolis, 2006.

REIGOTA, M. Meio Ambiente e representação social. $7^{a}$ ed. São Paulo: Cortez editora, 2007. p. 87. 
RIONDET-COSTA, D.R.T. Análise comparativa dos instrumentos de gestão em Unidades de Conservação visando a gestão participativa no Cone Sul. 2012. 388f. Tese (Doutorado em Meio Ambiente), Universidade do Estado do Rio de Janeiro, Rio de Janeiro, 2012.

RODRIGUES, A.S.L..; MALAFAIA, G. O meio ambiente na concepção de discentes no município de Ouro Preto/MG. Revista de estudos ambientais, v.11, n. 2, p. 44-58, jul./dez. 2009.

RODRIGUES, G.S.; PINTO, B.C.T.; FONSECA, L.C.S.; MIRANDA, C.C. O estado da arte das práticas didático-pedagógicas em Educação Ambiental (período de 2010 a 2017) na Revista Brasileira de Educação Ambiental. Revista Brasileira de Educação Ambiental, v. 14, n. 1, p. 9-28, 2019.

RUSCHEINSKY, A. Atores sociais e meio ambiente: a mediação da ecopedagogia. In: LAYRARGUES, P.P. (coord.). Identidades da Educação Ambiental brasileira. Diretoria de Educação Ambiental;. - Brasília: Ministério do Meio Ambiente, 2004. 156 p.

SANTAELLA, L. Percepção: fenomenologia, ecologia, semiótica. São Paulo: Cengage Learning. 146p. 2012.

SANTOS, F.P..; SOUZA, L.B. Estudo da percepção da qualidade ambiental por meio do método fenomenológico. Mercator. Fortaleza, v. 14, n. 2, p. 57-74, mai./ago. 2015.

SAUVÉ, L. Uma cartografia das correntes em Educação Ambiental. In: SATO, M.; CARVALHO, I.C.M. Educação Ambiental: pesquisa e desafios. Porto Alegre, 2005. $232 \mathrm{p}$.

SORRENTINO, M.; TRAJBER, R.; MENDONÇA, P.; JUNIOR, L.A.F. Educação Ambiental como política pública. Educação e Pesquisa, São Paulo, v. 31, n. 2, p. 285-299, mai./ago. 2005.

SOUSA, C.A.F.; ALVES, A.F.; ANDRADE, T.M.; NICODEMO, S.C.T.S.; VITORINO, G.O. A percepção ambiental de atores sociais de escolas públicas e privadas, em um bairro de João Pessoa (PB). Revista Brasileira de Educação Ambiental, São Paulo, v. 12, n. 4, p. 180-191, 2017

SOUZA, N.O.M.; SANTOS, F.R.P.; SALGADO, M.A.S.; ARAÚJO, F.F.S. Dez anos de história: avanços e desafios do Sistema Nacional de Unidades de Conservação da Natureza. In: MEDEIROS, R..; ARAÚJO, F.F.S. (Org.) Dez anos do Sistema Nacional de Unidades de Conservação da Natureza: lições do passado, realizações presentes e perspectivas para o futuro. Brasília, DF, MMA, p. 9-19. 2013.

TUAN, Yi-Fu. Topofilia - um estudo da percepção, atitudes e valores do meio ambiente. Ed. Difel: São Paulo, 1980. 248p. 